Jurnal Akuntansi Manajerial

ISSN (E): 2502-6704

Vol. 6, No. 1 Januari - Juni 2021: 1-17
Dipublikasikan oleh Fakultas Ekonomi dan Bisnis

Universitas 17Agustus 1945 Jakarta

http://journal.uta45jakarta.ac.id/index.php/JAM

\title{
Pengaruh Penerapan Psak 55 Dan Insentif Pajak Terhadap Agresivitas Pajak Dengan Corporate Social Responsibility (CSR) Sebagai Variabel Moderating
}

\author{
${ }^{1}$ Dimas Panji Setiawan, ${ }^{2}$ Ajeng Wijayanti \\ ${ }^{1}$ Mahasiswa Akuntansi Universitas 17 Agustus 1945 Jakarta \\ e-mail : dimaspanji702@gmail.com \\ ${ }^{2}$ Dosen FEB Universitas 17 Agustus 1945 Jakarta \\ e-mail: ajeng.wijayanti@uta45jakarta.ac.id
}

\begin{abstract}
ABSTRAK
Penelitian ini bertujuan untuk menguji pengaruh penerapan PSAK 55 dan insentif pajak terhadap agresivitas pajak dan corporate social responsibility sebagai variabel moderating. Penelitian ini menggunakan data sekunder dengan menggunakan pengumpulan data dokumentasi dan studi pustaka pada situs Bursa Efek Indonesia berupa laporan keuangan tahunan. Populasi yang digunakan dalam penelitian ini adalah perusahaan property \& real estate yang terdaftar di Bursa Efek Indonesia periode tahun 2015-2019 dengan teknik pengambilan sampel menggunakan purposive sampling method. Pengujian menggunakan analisis linear berganda dengan menggunakan bantuan STATA. Hasil dari penelitian ini menunjukan bahwa penerapan PSAK 55 tidak berpengaruh terhadap agresivitas pajak, intensif pajak berpengaruh terhadap agresivitas pajak, corporate social responsibility berpengaruh terhadap agresivitas pajak, dan corporate social responsibility tidak berhasil memoderasi pengaruh penerapaan PSAK 55 dan intensif pajak terhadap agresivitas pajak.
\end{abstract}

\section{ABSTRACT}

The aim of this study is to analyze the influence of application of PSAK 55 and tax intensive on tax aggressiveness and corporate social responsibility as moderating variables. This study uses secondary data using documentation data collection and literature study on the Indonesia Stock Exchange website in the form of annual financial reports. The population used in this study were proprty \& real estate companies listed on the Indonesia Stock Exchange period 2015-2019 with the sampling technique using purposive sampling method. The test uses multiple linear analysis using STATA. The results of this study indicate that the application of PSAK 55 has no effect on tax aggressiveness, tax intensive has effect on tax aggressiveness, corporate social responsibility has effect on tax aggressiveness, and corporate social responsibility does not succeed in moderating the effect of tax aggressiveness and tax intensity on tax aggressiveness.

\section{Info Artikel}

Diterima:27 Maret, 2021

Revisi: 15 Mei, 2021

Dipublikasi Online: 30 Juni 2021

\section{Kata Kunci:}

Penerapan PSAK 55, Insentif Pajak, Agresivitas Pajak, Corporate Social Responsibility

\section{Article History}

Received: March 27, 2021

Revised: May 15, 2021

Published Online: Juny 30,2021

\section{Keyword :}

The Application Of PSAK 55, Tax Intensive, Tax Aggressiveness, Corporate Social Responsibility

\section{PENDAHULUAN}

Pajak merupakan sumber penerimaan negara paling potensial yaitu $75-85 \%$, yang digunakan pemerintah untuk pembangunan dan peningkatan kesejahteraan Indonesia. Pembayaran pajak dibebankan kepada wajib pajak, baik orang pribadi atau badan yang mempunyai hak dan kewajiban perpajakan sesuai dengan ketentuan perundang-undangan. Wajib pajak badan antara lain meliputi sektor pertambangan, sektor konstruksi, sektor property \& real estate, sektor jasa keuangan, sektor perdagangan, dan sektor industri 
Jurnal Akuntansi Manajerial ISSN (E): 2502-6704

Vol. 6, No. 1 Januari - Juni 2021: 1-17
Dipublikasikan oleh Fakultas Ekonomi dan Bisnis

Universitas 17Agustus 1945 Jakarta http://journal.uta45jakarta.ac.id/index.php/JAM

pengolahan.Sistem perpajakan yang digunakan Indonesia yaitu self-assesment, yaitu wajib pajak dituntut untuk aktif dalam melakukan pembayaran pajak.

Property \& real estate merupakan suatu bidang usaha di bidang property, dimana seluruh rangkaian mulai dari pengadaan, pengelolaan, sampai pembangunan gedung dilakukan diatas tanah. Pada tahun 1974, pertama kalinya real estate diatur oleh pemerintah sebagai suatu industri. Kemudian pada tahun 2010, kondisi pasar property \& real estate di Indonesia mulai bangkit. Sub sektor property \& real estate dalam penerimaan pajak menyumbang secara berturut-turut sebesar 7,36\%,6,26\%, 6,80\%, dan 6,90\% pada tahun 2016, 2017, 2018, dan 2019. Dari data tersebut, terlihat bahwa kontribusi penerimaan pajak dari sub sektor property \& real estate mengalami naik-turun setiap tahunnya. Hal ini tidak sejalan dengan total aset dari sub sektor property \& real estate yang cenderung mengalami kenaikan setiap tahunnya. Berdasarkan data dari Bursa Efek Indonesia (BEI), rata-rata pertumbuhan total aset dari sub sektor property \& real estate pada tahun 2016 - 2019, berturut-turut sebesar 3,78 milyar rupiah, 3,82 milyar rupiah, 4,25 milyar rupiah, dan 4,37 milyar rupiah.

Perusahaan merupakan salah satu wajib pajak yang paling berperan dalam penerimaan pajak, semakin besar pajak yang dibayarkan oleh perusahaan, maka semakin besar juga penerimaan negara yang diterima (Rombe et al. 2017). Bagi pemerintah, hal ini sangat menguntungkan untuk pembiayaan dan pengalokasian pembangunan. Namun, bagi perusahaan pajak merupakan beban untuk mengurangi pendapatan, beban pajak yang tinggi akan berdampak pada menurunnya laba bersih perusahaan. Oleh karena itu, perusahaan melakukan agresivitas pajak, yaitu meminimalkan beban pajak, yang dilakukan secara legal maupun ilegal.

Berdasarkan laporan bersama IMF, International Center for Taxation and Development (ICTD) yang dianalisa kembali oleh PBB pada tahun 2016, Indonesia masuk peringkat ke 11 dari 30 negara yang melakukan agresivitas pajak dengan perkiraan nilai 6,48 miliar dolar AS (Pratiwi, 2018). Menurut ketua umum Real Estate Indonesia (REI), Setyo Maharso, dari total 3.000 pengembang, hanya 60\% yang melakukan pembayaran pajak sesuai peraturan, sedangkan $40 \%$ menggunakan penjualan berdasarkan harga mekanisme pasar bukan harga sebenarnya (Detik Finance 2018). Hal ini mengindikasikan bahwa terdapat banyak celah untuk melakukan penghindaran pajak pada sub sektor property \& real estate.

Corporate Social Responsibility (CSR), merupakan bentuk perhatian bisnis untuk menjamin agar praktek usahanya memenuhi kriteria tanggung jawab semua pemangku kepentingan, bukan hanya berorientasi pada laba semata. Pembayaran pajak merupakan salah satu bentuk dari kepatuhan dan tanggung jawab perusahaan terhadap investor dan masyarakat yang dibayarkan melalui pemerintah. Sikap perusahaan terhadap CSR dapat mempengaruhi keputusan perusahaan dalam melakukan agresivitas pajak.

Perlakuan instrumen keuangan berdasarkan Peraturan Standar Akuntansi Keuangan (PSAK) merupakan faktor terkait agresivitas pajak. PSAK 55 merupakan Standar Akuntasni Keuangan yang mengatur pengakuan dan pengukuran instrumen keuangan, 
Jurnal Akuntansi Manajerial ISSN (E): 2502-6704

Vol. 6, No. 1 Januari - Juni 2021: 1-17
Dipublikasikan oleh Fakultas Ekonomi dan Bisnis

Universitas 17Agustus 1945 Jakarta http://journal.uta45jakarta.ac.id/index.php/JAM

yang dalam hal ini termasuk pengakuan aset keuangan. Faktor lain yang berkaitan dengan agresivitas pajak adalah adanya pemberian insentif, berupa penurunan tarif pajak penghasilan pada badan perseroan terbuka memungkinkan perusahaan melakukan tax avoidance (Rombe et al. 2017). Penelitian ini bertujuan untuk menguji pengaruh penerapan PSAK 55 dan insentif pajak terhadap agresivitas pajak dan corporate social responsibility (CSR) sebagai variabel moderating

\section{LITERATUR REVIEW DAN HIPOTESIS}

\section{Teori Perilaku Terencana (Theory of Planned Behavior)}

Theory of Planned Behavior merupakan teori yang digunakan untuk memperkirakan tingkah laku seseorang (Wikamorys \& Rochmach, 2017). Teori perilaku terencana menjelaskan perilaku yang direncanakan termasuk perencanaan pajak yang dilakukan perusahaan. Penghindaran pajak yang dilakukan perusahaan merupakan hasil kebijakan perusahaan dan bukan merupakan suatu kebetulan.

\section{Teori Keagenan (Agency Theory)}

Teori keagenan merupakan bentuk kontraktual antara seseorang atau beberapa orang sebagai principal (pemegang saham) dan seseorang atau beberapa orang lainnya sebagai agen (pengelola perusahaan), dimana agen memberikan pelayanan untuk kepentingan principal dan pendelegasian wewenang untuk membuat keputusan dari principal kepada agen (Anthony and Govindarajan, 2012). Teori agensi dalam agresivitas pajak menjelaskan adanya pemberian tugas yang diberikan oleh pihak prinsipal kepada pihak agen, yang menuntut pihak agen untuk selalu memberikan kinerja yang baik agar dapat meningkatkan kualitas perusahaan. Salah satu langkah yang diambil oleh agen adalah dengan meminimalkan beban pajak yang diharapkan laba perusahaan akan meningkat.

\section{Teori Legitimasi (Legitimacy Theory)}

Teori legitimasi memfokuskan pada kewajiban perusahaan untuk memastikan bahwa mereka beroperasi dalam bingkai dan norma yang sesuai dalam lingkungan masyarakat dimana perusahaan itu berdiri (Ningsih and Cheisviyanny 2019). Perusahaan membutuhkan pengakuan masyarakat dengan cara mengungkapkan dan menerapkan Corporate Social Responsibility (CSR) agar perusahaan dapat diterima dengan baik oleh masyarakat. Pengungkapan CSR oleh perusahaan memberikan imagepostif dimata para stakeholdernya, sehingga dapat menunjang keberlangsungan hidup perusahaan tersebut.

\section{Hipotesis}

\section{Pengaruh PSAK 55 Terhadap Agresivitas Pajak}

PSAK merupakan acuan atau pedoman yang mengatur prinsip dalam membuat dan menyajikan laporan keungan yang sesuai dengan standar dan aturan yang berlaku secara umum. Nurhandono \& Amrie (2017) menjelaskan bahwa agresivitas pajak dapat dilakukan karena terdapat kesempatan bagi wajib pajak untuk menunda pembayaran, adanya perbedaan tarif antara pajak penghasilan dengan transaksi khusus dan adanya perbedaan perlakuan pajak karena perbedaan karakteristik transaksi. Penelitian yang secara langsung 
Jurnal Akuntansi Manajerial ISSN (E): 2502-6704

Vol. 6, No. 1 Januari - Juni 2021: 1-17
Dipublikasikan oleh Fakultas Ekonomi dan Bisnis

Universitas 17Agustus 1945 Jakarta http://journal.uta45jakarta.ac.id/index.php/JAM

meneliti agresivitas pajak dengan instrumen keuangan adalah penelitian yang dilakukan oleh Lee (2015) dan Nurhandono \& Amrie (2017) yang membuktikan bahwa terdapat pengaruh positif signifikan antara penerapan instumen keuangan berdasarkan SAK dengan agresivitas pajak. Berdasarkan penelitian terdahulu penjelasan dari latar belakang penelitian, maka ditetapkan hipotesis pertama adalah $\mathrm{H}_{1}$ : Penerapan PSAK 55 berpengaruh signifikan terhadap agresivitas pajak.

\section{Pengaruh Intensif Pajak Terhadap Agresivitas Pajak}

Insentif pajak merupakan suatu kebijakan perpajakan yang memberikan kemudahan kepada pihak-pihak terkait dengan tujuan untuk meningkatkan kemajuan nasional dalam hal berinvestasi. Penelitian akuntansi terkait intensif pajak dengan agresivitas pajak telah dilakukan oleh Nuritomo dan Martani (2014), dan Rombe et al., (2017) yang menyatakan bahwa intensif pajak berpengaruh positif terhadap agresivitas pajak. Berdasarkan penelitian terdahulu dan latar belakang penelitian, maka ditetapkan hipotesis 2 adalah $\mathrm{H}_{2}$ : Insentif pajak berpengaruh signifikan terhadap agresivitas pajak.

\section{Pengaruh Corporate Social Responsibility Terhadap Agresivitas Pajak}

Corporate Social Responsibility (CSR) adalah suatu konsep bahwa perusahaan memiliki dan mempunyai berbagai tanggung jawab termasuk kepada semua yang berkepentingan seperti konsumen, karyawan, pemegang saham, komunitas dan juga lingkungan dalam segala aspek operasional yang melingkupi aspek ekonomi, sosial, dan lingkungan. Dalam penelitian terdahulu yang dilakukan Lanis dan Richardson (2012), Huseynov dan Klam (2012) dalam penelitiannya membahas hubungan antara pengungkapan CSR dengan agresivitas pajak. Hasil penelitian menunjukkan bahwa semakin tinggi tingkat pengungkapan CSR dari suatu perusahaan, semakin rendah tingkat agresivitas pajak perusahaan tersebut. Berdasarkan latar belakang dan penelitian terdahulu, maka ditetapkan hipotesis 3 adalah $\mathrm{H}_{3}$ : Corporate social reponsibility berpengaruh signifikan terhadap agresivitas pajak.

\section{Pengaruh PSAK 55 Terhadap Agresivitas Pajak yang Dimoderasi Corporate Social Responsibility}

PSAK secara rinci mencakup petunjuk mengenai tata cara pembuatan laporan keuangan, baik dari proses pencatatan, penyusutan, perlakuan, hingga penyajian laporan keuangan. Penelitian yang dilakukan oleh Lee (2015) dan Nurhandono \& Amrie (2017) yang membuktikan bahwa terdapat pengaruh positif signifikan antara perlakuan akuntansi dengan agresivitas pajak. Hasil studi yang dilakukan PIRAC (organisasi sumber daya nirlaba dan independen yang memberikan pelayanan dalam bentuk penelitian, pelatihan, advokasi, dan penyebaran informasi) menyatakan bahwa semakin tinggi pengungkapan CSR maka semakin tinggi agresivitas pajak (Hidayat et al. 2016). Berdasarkan penelitian terdahulu dan latar belakang penelitian, maka ditetapkan hipotesis 4 adalah $\mathrm{H}_{4}$ : Corporate social responsibility memoderasi pengaruh PSAK 55 terhadap agresivitas pajak. 
Jurnal Akuntansi Manajerial

ISSN (E): 2502-6704

Vol. 6, No. 1 Januari - Juni 2021: 1-17
Dipublikasikan oleh Fakultas Ekonomi dan Bisnis

Universitas 17Agustus 1945 Jakarta http://journal.uta45jakarta.ac.id/index.php/JAM

\section{Pengaruh Insentif Pajak Terhadap Agresivitas Pajak yang Dimoderasi Corporate Social Responsibility}

Dalam konteks Indonesia belum banyak penelitian yang dilakukan terkait CSR dan agresivitas pajak, khususnya jika dihubungkan dengan insentif pajak atas CSR sesuai Undang-Undang No. 36 tahun 2008 tentang Perubahan Keempat Undang-Undang Pajak Penghasilan (UU PPh) dan Pemerintah Nomor 93 tahun 2010 serta Peraturan Menteri Keuangan Nomor 76 tahun 2011. Penelitian akuntansi terkait Intensif pajak terhadap agresivitas pajak yang di moderasi oleh CSR telah dilakukan oleh Hidayat et al., (2016) semakin tinggi pengungkapan CSR maka semakin rendah agresivitas pajak, terutama pada saat perusahaan memanfaatkan insentif pajak yang diberikan oleh pemerintah berupa tax deduction atas CSR. Dalam penelitian tersebut CSR sebagai variable moderating memperkuat hubungan antara insentif pajak dengan agresivitas pajak. Berdasarkan penelitian terdahulu dan latar belakang penelitian, maka hipotesis 5 adalah $\mathrm{H}_{5}$ : Corporate social responsibility memoderasi pengaruh insentif pajak terhadap agresivitas pajak.

\section{METODE PENELITIAN}

\section{Objek Penelitian}

Objek penelitian ini adalah perusahaan sub sektor property \& real estate yang terdaftar di Bursa Efek Indonesia (BEI).

\section{Populasi dan Sampel}

Populasi penelitian ini adalah perusahaan property \& real estate yang terdaftar di BEI pada periode 2015-2019, sebanyak 62 perusahaan. Teknik pengambilan sampel menggunakan purposive sampling dengan kriteria sebagai berikut :

1. Perusahaan sub sektor property \& real estate yang secara konsisten terdaftar dari tahun $2015-2019$.

2. Perusahaan yang melaporkan laporan keuangan dalam satuan rupiah kepada BEI untuk periode yang berakhir pada tanggal 31 Desember tahun 2015 - 2019, dengan tujuan untuk meningkatkan komprabilitas atau daya banding yang baik.

\section{Jenis dan Sumber Data}

Jenis data yang digunakan pada penelitian ini adalah data sekunder, yaitu sumber data berasal dari laporan tahunan perusahaan property \& real estate yang terdaftar di BEI periode 2015 - 2019 .

\section{Teknik Pengumpulan Data}

Teknik pengumpulan data yang digunakan pada penelitian ini adalah, mengumpulkan data sekunder dari perusahaan yang terdaftar di BEI, kemudian pengambilan sampel menggunakan metode purposive sampling. 
Jurnal Akuntansi Manajerial

ISSN (E): 2502-6704

Vol. 6, No. 1 Januari - Juni 2021: 1-17
Dipublikasikan oleh Fakultas Ekonomi dan Bisnis

Universitas 17Agustus 1945 Jakarta http://journal.uta45jakarta.ac.id/index.php/JAM

\section{Definisi dan Operasional Variabel}

Variabel penelitian ini menggunakan variabel independen, dependen, dan moderating.

1. Variabel PSAK $55\left(\mathrm{X}_{1}\right)$

PSAK 55 diproyeksikan menggunakan variabel dummy,

1 = perusahaan menerapkan PSAK 55

$0=$ perusahaan belum menerapkan PSAK 55

2. Variabel Insentif Pajak $\left(\mathrm{X}_{2}\right)$

Pengukuran variabel $\mathrm{X}_{2}$ menurut Yin \& Cheng (2004) dan Harini et al., (2020).

$$
\text { TAXPLAN }=\frac{\text { Tarif Pajak } x(P T I-C T E)}{\text { Total Aset }}
$$

3. Variabel Agresivitas Pajak (Y)

Agresivitas pajak diukur menggunakan effective tax rate (ETR).

$$
E T R=\frac{\text { Beban PPh }}{\text { Laba Sebelum Pajak }} 100 \%
$$

4. Variabel Corporate Social Responsibility (Z)

Pengukuran variabel Z menurut Atmajaya (2015) dan Abdul \& Ariwendha (2017).

$$
\operatorname{CSRI} j=\frac{\sum X i j}{n j}
$$

\section{Metode Analisis Data}

\section{Analisis Statistik Deskriptif}

Statistik deskriptif berusaha untuk memberikan gambaran atau deskripsi atas suatu data yang berasal dari suatu sampel, yang dapat dilihat dari rata-rata (mean), standar deviasi (ukuran jarak tiap nilai terhadap mean, variance, maksimum dan minimum (Ghozali 2016).

\section{Pemilihan Metode Estimasi}

Widarjono (2013), menyatakan bahwa ada tiga pendekatan yang dapat dilakukan untuk mengestimasi parameter model menggunakan data panel, yaitu:

\section{a) common effect}

Dalam metode in diasumsikan bahwa perilaku data perusahaan sama dalam berbagai kurun waktu. Hasil pengujian ini akan digunakan untuk pengujuan asumsi klasik.

\section{b) fixed effect}

Pendekatan model ini mengasumsikan bahwa perbedaan antar individu dapat diakomodasi dari perbedaan intersepnya. Residual dari persamaan ini dapat digunakan untuk pengujian Hausman test.

c) random effect

Pendekatan random effect mengestimasikan data panel dimana variabel gangguan mungkin saling berhubungan antar waktu dan individu. Residual dari persamaan ini dapat digunakan untuk hausman test. 
Jurnal Akuntansi Manajerial

ISSN (E): 2502-6704

Vol. 6, No. 1 Januari - Juni 2021: 1-17
Dipublikasikan oleh Fakultas Ekonomi dan Bisnis

Universitas 17Agustus 1945 Jakarta http://journal.uta45jakarta.ac.id/index.php/JAM

\section{Penentuan Metode Estimasi Regresi}

a) Pengujian chow, untuk memilih antara model pada regresi data panel yaitu antara model FEM (Fixed Effect Model) dengan CEM (Common Effect Model).

b) Pengujian lagrange multiplier, digunakan untuk memilih antara model CEM (Common Effect Model) dan model REM (Random Effect ModeI).

c) Pengujian Hausman, digunakan untuk memilih antara model FEM (Fixed Effect Model) dan model REM (Random Effect ModeI). Model fixed effect memiliki keunggulan dalam membedakan effect waktu dan effect individual. Kemudian random effect mempunyai keunggulan memiliki parameter lebih sedikit yang mengakibatkan model random effect memiliki derajat kebebasan yang lebih besar dibandingkan dengan fixed effect.

\section{Asumsi Klasik}

a) Uji normalitas

Uji normalitas yag digunakan adalah kolmogrov smirnov dengan menggunakan taraf signifikansi 5\% jika nilai signifikansi< $<, 05$ maka data tidak berdistribusi secara normal (Ghozali 2016).

b) Uji heteroskedastisitas

Uji heteroskedastisitas bertujuan untuk menguji dalam model regresi terjadi kesaman atau ketidaksamaan varian dari residual satu pengamatan kepengamatan yang lain. Jika variansi dari residual satu pengamatan ke pengamatan lain tetap maka disebut homoskedastisitas dan jika berbeda disebut heteroskedasitas (Ghozali, 2016).

c) Uji multikolinearitas

Multikolinearitas bertujuan untuk menguji apakah di dalam model analisis regresi ditemukan adanya korelasi antar variabel bebas (independen). Jika nilai tolerance $\leq 0,10$ atau nilai VIF $\geq 10$, maka terjadi multikolonieritas. Namun, jika nilai tolerance $\geq 0,10$ atau nilai $\mathrm{VIF} \leq 10$, maka tidak terjadi multikolonieritas (Ghozali, 2016).

d) Uji autokorelasi

Uji autokorelasi bertujuan untuk mengetahui hubungan yang kuat baik positif maupun negatif atau tidak ada hubungan antar data yang ada pada variabel-variabel penelitian dalam model regresi linier. Pengujian dilakukan dengan menggunakan pengukuran Durbin Watson dengan ketentuan jika Durbin Watson (d) lebih kecil dari DL atau lebih besar dari (4_dL) maka H0 ditolak dan menunjukan adanya autokorelasi, jika Durbin Watson (d) terletak antara DU dan (4-dL) maka H0 diterima dan tidak terjadi autokorelasi, nilai dU dan dL bisa dilihat pada tabel Durbin Watson dengan ketentuan $(\mathrm{k} ; \mathrm{N})$ dimana $\mathrm{k}$ adalah variabel independen dan $\mathrm{N}$ adalah sampel pada penelitian. 
Jurnal Akuntansi Manajerial

ISSN (E): 2502-6704

Vol. 6, No. 1 Januari - Juni 2021: 1-17
Dipublikasikan oleh Fakultas Ekonomi dan Bisnis

Universitas 17Agustus 1945 Jakarta http://journal.uta45jakarta.ac.id/index.php/JAM

\section{Analisis Regresi Linear Berganda}

Penelitian ini menggunakan regresi berganda untuk mengetahui seberapa besar pengaruh penerapan PSAK 55 dan insentif Pajak terhadap agresivitas pajak, dan pengaruh corporate social responsibility dalam memoderasi.

$$
E T R=\beta 0+P S A K+T A X P L A N+C S R+e
$$

\section{Pengujian Hipotesis}

Uji hipotesis bertujuan untuk menentukan apakah hipotesis nol (Ho) dapat ditolak dan diganti dengan hipotesis alternatif (Ha) (Sekaran and Bougie 2016). Jika $\mathrm{H}_{0}$ ditolak maka dapat diartikan bahwa ada pengaruh variabel independen terhadap variabel dependen. Kriteria pengambilan keputusan dalam uji hipotesis adalahjika nilai signifikansi < 0,05 maka H0 ditolak, berarti variabel independen berpengaruh signifikan terhadap variabel dependen. Jika signifikansi $\geq 0,05$ maka $\mathrm{H}_{0}$ diterima, berarti variabel independen tidak berpengaruh signifikan terhadap variabel dependen (Ghozali, 2016).

\section{HASIL DAN PEMBAHASAN}

\section{Statistik Deskriptif}

Tabel 4.1 Hasil Uji Analisis Deskriptif

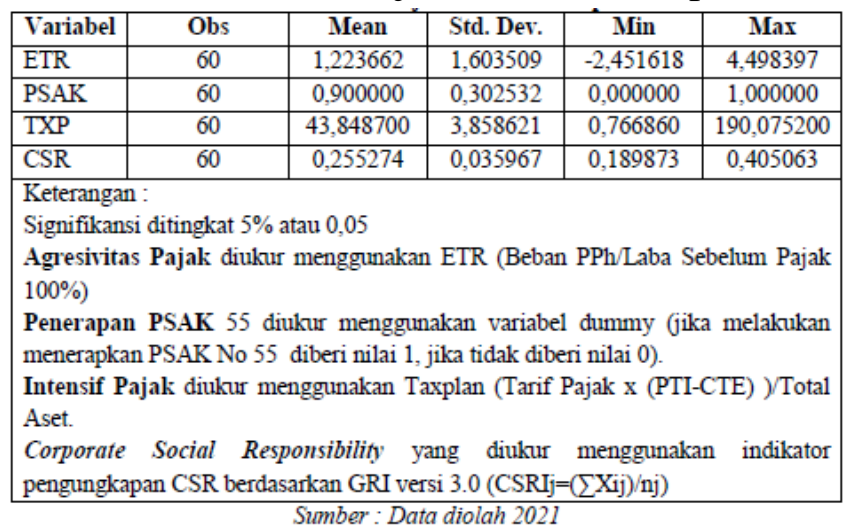

Berdasarkan tabel deskriptif diatas, dapat dijelaskan bahwa, agresivitas pajak (ETR) menunjukkan nilai minimun sebesar -2.451618, nilai maksimum sebesar 4.498397 dengan Std Dev sebesar 1.603509. Hal ini menunjukkan bahwa rata-rata perusahaan property \& real estate di BEI memiliki nilai agresivitas pajak sebesar 1,223662. Penerapan PSAK 55 (PSAK) menunjukkan nilai minimun sebesar 0, nilai maksimum sebesar 1 dengan Std Dev sebesar 0,3025317. Hal ini menunjukkan bahwa rata-rata perusahaan property \& real estate di BEI memiliki nilai penerapan PSAK 55 sebesar 0,9.

Intensif pajak (TXP) menunjukkan nilai minimun sebesar 0,7668599, nilai maksimum sebesar 190,0752 dengan Std Dev sebesar 38,58621. Hal ini menunjukkan bahwa rata-rata perusahaan property \& real estate di BEI memiliki nilai intensif pajak sebesar 43,8487. 
Jurnal Akuntansi Manajerial

ISSN (E): 2502-6704

Vol. 6, No. 1 Januari - Juni 2021: 1-17
Dipublikasikan oleh Fakultas Ekonomi dan Bisnis

Universitas 17Agustus 1945 Jakarta http://journal.uta45jakarta.ac.id/index.php/JAM

Corporate social responsibility menunjukkan nilai minimun sebesar 0,189873, nilai maksimum sebesar 0,3797468 dengan Std Dev sebesar 0,035967. Hal ini menunjukkan bahwa rata-rata perusahaan property \& real estate di BEI memiliki nilai corporate social responsibility sebesar 0,255274.

\section{Uji Korelasi}

Tabel 4.2 Uji Korelasi

\begin{tabular}{|l|l|l|l|l|}
\hline & ETR & PSAK & TXP & CSR \\
\hline ETR & 1.0000 & & & \\
\hline PSAK & 0.0721 & 1.0000 & & \\
\hline TXP & 0.2972 & -0.0248 & 1.0000 & \\
\hline CSR & 0.1512 & 0.0197 & 0.3003 & 1.0000 \\
\hline \multicolumn{5}{|c|}{ Sumber: Data sekander yang diolah, 2021 }
\end{tabular}

Dari hasil uji korelasi diatas, antara $\mathrm{X}_{1}$ (penerapan PSAK 55) dengan $\mathrm{Y}$ (agresivitas pajak) memiliki nilai korelasi sebesar 0.0721 yang artinya tidak ada masalah multikolinearitas karena nilai korelasi tidak lebih dari 0,75. Sedangkan nilai variabel $\mathrm{X}_{2}$ (intensif pajak) dengan variabel y (agresivitas pajak) memiliki nilai korelasi sebesar 0.2972 yang artinya tidak ada masalah multikolinearitas karena nilai korelasi tidak lebih dari 0,75 . Serta nilai variabel Z (corporate social responsibility) memiliki nilai korelasi sebesar 0,1512 yang artinya tidak ada masalah multikolinearitas karena nilai korelasi tidak lebih dari 0,75.

\section{Pemilihan Metode Estimasi}

Tabel 4.3 Hasil Pengujian Common Effect Model

\begin{tabular}{|l|c|c|c|r|}
\hline \multicolumn{1}{|c|}{ ETR } & Coef. & Std. Err & T & P>t \\
\hline PSAK & 0,4598291 & 0,649842 & 0,71 & 0,482 \\
\hline TXP & 0,0157719 & 0,005341 & 2,95 & 0,005 \\
\hline CSR & $-11,897940$ & 5,728786 & $-2,08$ & 0,042 \\
\hline Cons & 3,155476 & 1,525607 & 2,07 & 0,043 \\
\hline Number of obs & & 60 \\
\hline F (3, 56) & & 3,54 \\
\hline Prob $>$ F & 0.1238 \\
\hline R-squared & 0,1594 \\
\hline Root MSE & 0,1144 \\
\hline
\end{tabular}

Tabel 4.4 Hasil Pengujian Fixede Effect Model

\begin{tabular}{|c|c|c|c|c|}
\hline ETR & Coef. & Std. Err & $\mathbf{T}$ & $P>t$ \\
\hline PSAK & -.2214298 & .4598946 & -0.48 & 0.633 \\
\hline TXP & -.000555 & .0048136 & -0.12 & 0.909 \\
\hline CSR & 3,027009 & 5,336324 & 0.57 & 0.573 \\
\hline Cons & .6745678 & 1,438056 & 0.47 & 0.641 \\
\hline \multicolumn{4}{|c|}{ Number of obs } & 60 \\
\hline \multicolumn{4}{|c|}{ Number of groups } & 12 \\
\hline \multicolumn{4}{|c|}{$\mathrm{F}(3,117)$} & 0,18 \\
\hline \multicolumn{4}{|l|}{ Prob $>F$} & 0,9127 \\
\hline \multicolumn{4}{|l|}{ sigma_u } & 1,50745590 \\
\hline \multicolumn{4}{|l|}{ sigma_e } & 0,85426894 \\
\hline rho & 0,75691968 & \multicolumn{3}{|c|}{ (fraction of variance due to $u \_i$ ) } \\
\hline
\end{tabular}

Tabel 4.5 Hasil Pengujian Random Effect Model 
Jurnal Akuntansi Manajerial

ISSN (E): 2502-6704

Vol. 6, No. 1 Januari - Juni 2021: 1-17
Dipublikasikan oleh Fakultas Ekonomi dan Bisnis

Universitas 17Agustus 1945 Jakarta http://journal.uta45jakarta.ac.id/index.php/JAM

\begin{tabular}{|c|c|c|c|c|}
\hline ETR & Coef. & Std. Err & $\mathrm{Z}$ & $\mathrm{P}>\mathrm{Z}$ \\
\hline PSAK & -.085553 & .4624576 & -0.18 & 0.853 \\
\hline TXP & .0022568 & .0046122 & 0.49 & 0.625 \\
\hline CSR & .6736192 & 5 & 0.13 & 0.895 \\
\hline Cons & 1,029743 & 1,406609 & 0.73 & 0.464 \\
\hline \multicolumn{4}{|c|}{ Number of obs } & 60 \\
\hline \multicolumn{4}{|c|}{ Number of groups } & 12 \\
\hline \multicolumn{4}{|c|}{ Wald chi2(3) } & 0,33 \\
\hline \multicolumn{4}{|c|}{ Prob > chi 2} & 0,9539 \\
\hline \multicolumn{4}{|c|}{ sigma_u } & 1,21451550 \\
\hline \multicolumn{4}{|l|}{ sigma_e } & 0,85426894 \\
\hline rho & $0,66900 \mathrm{~s}$ & fraction o & ce dut & \\
\hline
\end{tabular}

Sumber : Data Sekunder yang diolah, 2021

\section{Penentuan Metode Estimasi}

\section{Tabel 4.6 Hasil Uji Chow}

\begin{tabular}{|l|r|}
\hline \multicolumn{1}{|c|}{ Test Summary } & Prob \\
\hline Prob $>$ F & 0,9127 \\
\hline sigma_u & 1,50745590 \\
\hline sigma_e & 0,85426894 \\
\hline \multicolumn{2}{|c|}{ Sumber: Data sekumder yang diolah, 2021}
\end{tabular}

Prob>F dalam penelitian ini sebesar 0.9127 atau lebih besar dari 0,5 artinya model common effect lebih tepat digunakan daripada fixed effect.

Tabel 4.7 Hasil Uji Lagrange Multiplier

\begin{tabular}{|c|c|}
\hline Test Summary & Prob \\
\hline Prob $>$ chi2 & 0.000 \\
\hline
\end{tabular}

Sumber: Data sekunder yang diolah, 2021

Nilai prob>chi2 lebih kecil dari tingkat signifikansi yaitu 0.000. Maka, modelrandom effect lebih baik daripadacommon effect.

Tabel 4.8 Hasil Uji Hausman

\begin{tabular}{|c|c|}
\hline Test Summary & Prob \\
\hline Prob $>$ chi2 & 0.0001 \\
\hline
\end{tabular}

Sumber: Data sekunder yang diolah, 2021

Nilai prob>chi2 sebesar 0.0001 atau lebih kecil dari tingkat signifikansi $(0,05)$, artinya model fixedeffect lebih baik dari pada random effect. 
Jurnal Akuntansi Manajerial

ISSN (E): 2502-6704

Vol. 6, No. 1 Januari - Juni 2021: 1-17
Dipublikasikan oleh Fakultas Ekonomi dan Bisnis

Universitas 17Agustus 1945 Jakarta http://journal.uta45jakarta.ac.id/index.php/JAM

\section{Uji Asumsi Klasik}

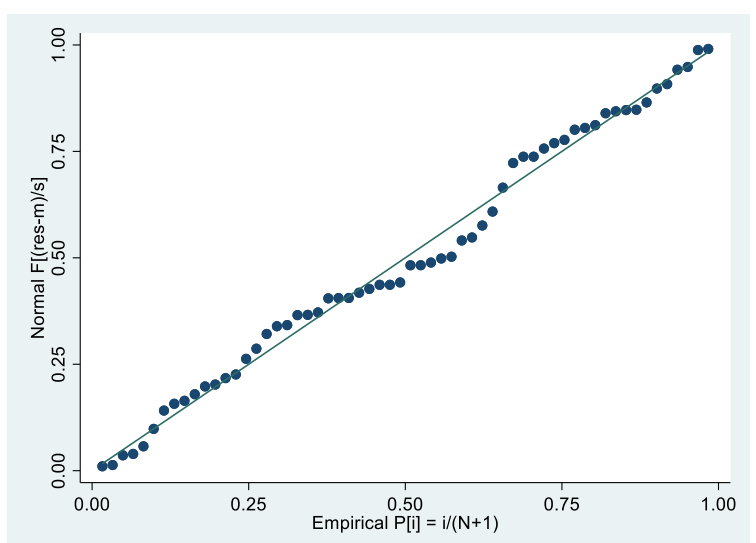

Gambar 4.1 Hasil Uji Normalitas Grafik Probability Plot

Sumber : Data sekunder yang diolah, 2021

Pada gambar 4.1 data terlihat menyebar disekitar garis diagonal dan mengikuti arah garis diagonalnya, maka dapat diartikan model regresi memenuhi asumsi normalitas. Kemudian uji normalitas dengan menggunakan shapiro wilk test dijelaskan sebagai berikut:

Tabel 4.9 Hasil Uji Normalitas Shapiro Wilk Test

\begin{tabular}{|l|c|}
\hline \multicolumn{1}{|c|}{ Test Summary } & Prob \\
\hline Obs & 60 \\
\hline Prob $>z$ & 0,76791 \\
\hline
\end{tabular}

Sumber: Data sekunder yang diolah, 2021

Nilai Prob>z sebesar 0,768 atau lebih besar dari 0,05, maka dapat disimpulkan bahwa pengujian ini lulus uji normalitas.

Tabel 4.10 Hasil Uji Multikorelasi

\begin{tabular}{|l|c|c|}
\hline Variabel & VIF & Tolerance \\
\hline PSAK & 1,10 & 0.908884 \\
\hline TXP & 1,10 & 0.909090 \\
\hline CSR & 1,00 & 0.998573 \\
\hline \multicolumn{2}{|c|}{ Sumber: Data sekunder yang diolah, 2021 }
\end{tabular}

Hasil uji multikolonieritas pada tabel 4.10 menunjukkan bahwa tidak ada satupun variabel independen (variabel bebas) yang memiliki nilai tolerance diatas 0,10 dan nilai Variance Inflation Factor (VIF) di bawah 10. Nilai VIF variabel PSAK55 sebesar 1,10, variabel TXP sebesar 1,10 dan variabel CSR sebesar 1,00. Jadi dapat disimpulkan bahwa tidak terjadi multikolonieritas antar variabel bebas dalam model regresi ini. 
Jurnal Akuntansi Manajerial

ISSN (E): 2502-6704

Vol. 6, No. 1 Januari - Juni 2021: 1-17
Dipublikasikan oleh Fakultas Ekonomi dan Bisnis

Universitas 17Agustus 1945 Jakarta http://journal.uta45jakarta.ac.id/index.php/JAM

Tabel 4.11 Hasil Uji Heteroskedastisitas

\begin{tabular}{|l|c|}
\hline \multicolumn{1}{|c|}{ Test Summary } & Prob \\
\hline Chi2 & 0,61 \\
\hline Prob>chi2 & 0,4364 \\
\hline
\end{tabular}

Sumber: Data sekunder yang diolah, 2021

Nilai Prob > chi2 sebesar 0,4364 atau lebih besar dari 0,05, maka dapat disimpulkan bahwa pengujian ini lulus uji heteroskedastisitas.

\begin{tabular}{|l|c|}
\hline \multicolumn{1}{|c|}{ Test Summary } & Prob \\
\hline Wald chi2(3) & 11,38 \\
\hline Prob>chi2 & 0.0980 \\
\hline
\end{tabular}

Sumber: Data sekunder yang diolah, 2021

Tabel 4.12 Hasil Uji Autokorelasi

Hasil uji STATA untuk autokorelasi pada tabel 4.12 menunjukan bahwa nilai Prob > chi2 sebesar 0,0980 >0,05. Maka dapat disimpulkan bahwa pengujian pada penelitian ini bebas autokorelasi.

\section{Uji Regresi Linear Berganda}

Tabel 4.13 Hasil Regresi Linear Berganda dengan Menggunakan Common Effect

Model
\begin{tabular}{|l|c|c|c|r|}
\hline \multicolumn{1}{|c|}{ ETR } & Coef. & Std. Err & T & \multicolumn{1}{c|}{ P>t } \\
\hline PSAK & 0,4598291 & 0,649842 & 0,71 & 0,482 \\
\hline TXP & 0,0157719 & 0,005341 & 2,95 & 0,005 \\
\hline CSR & $-11,897940$ & 5,728786 & $-2,08$ & 0,042 \\
\hline Cons & 3,155476 & 1,525607 & 2,07 & 0,043 \\
\hline Number of obs & & 60 \\
\hline F( 3, 56) & & 3,54 \\
\hline Prob > F & 0.1238 \\
\hline R-squared & 0,1594 \\
\hline Root MSE & & 0,1144 \\
\hline
\end{tabular}

Berdasarkan persamaan regresi berganda diatas diketahui bahwa nilai constant untuk persamaan regresi (a) adalah 1,127.824. Hal ini dapat disimpulkanbahwa apabila nilai penerapan PSAK, intensif pajak dan corporate social responsibility bernilai 0 , maka agresivitas pajak bernilai 1,127.824, dengan nilai interpretasi hasil disajikan sebagai berikut:

a. Variabel PSAK 55 menunjukkan koefisien regresi sebesar 0,4598291 dengan tingkat signifikansi (p) value sebesar 0,787 lebih besar dari $\alpha=5 \%$.

b. Variabel TXP menunjukkan koefisien regresi sebesar 0,0157719dengan tingkat signifikansi (p) value sebesar 0,746 lebih besar dari $\alpha=5 \%$.

c. Variabel CSR menunjukkan koefisien regresi sebesar -11,897940dengan tingkat signifikansi (p) value sebesar 0,841 lebih besar dari $\alpha=5 \%$.

Hasil pengujian terhadap koefisien regresi menghasilkan model berikut ini: $E T R=3,155+-0,460 P S A K+0,016 T A X P L A N \pm 11,898 C S R+e$ 
Jurnal Akuntansi Manajerial

ISSN (E): 2502-6704

Vol. 6, No. 1 Januari - Juni 2021: 1-17
Dipublikasikan oleh Fakultas Ekonomi dan Bisnis

Universitas 17Agustus 1945 Jakarta http://journal.uta45jakarta.ac.id/index.php/JAM

\section{Hasil Uji Hipotesis}

Tabel 4.14 Hasil Pengujian Hipotesis

\begin{tabular}{|l|c|c|c|r|}
\hline \multicolumn{1}{|c|}{ ETR } & Coef. & Std. Err & T & P>t \\
\hline PSAK & 0,4598291 & 0,649842 & 0,71 & 0,482 \\
\hline TXP & 0,0157719 & 0,005341 & 2,95 & 0,005 \\
\hline CSR & $-11,897940$ & 5,728786 & $-2,08$ & 0,042 \\
\hline Cons & 3,155476 & 1,525607 & 2,07 & 0,043 \\
\hline Number of obs & 60 \\
\hline F( 3, 56) & 3,54 \\
\hline Prob $>$ F & 0.1238 \\
\hline R-squared & 0,1594 \\
\hline Root MSE & 0,1144 \\
\hline
\end{tabular}

Tabel 4.15 Hasil Penelitian Moderating Menggunakan Random Effect Model

\begin{tabular}{|l|c|c|c|r|}
\hline \multicolumn{1}{|c|}{ ETR } & Coef. & Std. Err & T & P $>$ t \\
\hline PSAKCSR & -.7884592 & 2,449823 & -0.32 & 0.749 \\
\hline TXPCSR & .034966 & .0187783 & 1.86 & 0.068 \\
\hline Cons & .9992554 & .606836 & 1.65 & 0.105 \\
\hline Number of obs & & 60 \\
\hline F(3, 56) & 1,73 \\
\hline Prob $>$ F & 0,1857 \\
\hline R-squared & 0,0574 \\
\hline Adj R-squared & 0,0243 \\
\hline
\end{tabular}

\section{Hipotesis Pertama}

Hasil pengujian hipotesis tentang pengaruh penerapan PSAK55 terhadap agresivitas pajak menunjukkan nilai signifikansi 0,482 lebih besar dari $\alpha=5 \%$. Hal ini berarti bahwa hipotesis pertama ditolak. Hasil analisis menyatakan bahwa nilai $\mathrm{P}$ value $>0.05$ maka variabel $\mathrm{X}_{1}$ (penerapan PSAK 55) terhadap agresivitas pajak tidak berpengaruh. Hasil ini tidak sejalan dengan penelitian yang dilakukan oleh Lee (2015) dan Nurhandono \& Amrie (2017) yang membuktikan bahwa terdapat pengaruh positif signifikan antara penerapan instumen keuangan berdasarkan SAK dengan agresivitas pajak.

\section{Hipotesis Kedua}

Hasil pengujian hipotesis tentang pengaruh intensif pajak terhadap agresivitas pajak menunjukkan nilai signifikansi 0,005 lebih kecil dari $\alpha=5 \%$. Hal ini berarti bahwa hipotesis kedua diterima. Hasil analisis menyatakan bahwa nilai $\mathrm{P}$ value< 0.05 maka variabel $\mathrm{X}_{2}$ (insentif pajak) terhadap agresivitas pajak berpengaruh. Hasil penelitian ini sejalan dengan penelitian yang dilakukan oleh Nuritomo dan Martani (2014), dan Rombe et al., (2017) yang menyatakan bahwa intensif pajak berpengaruh positif terhadap agresivitas pajak.

\section{Hipotesis Ketiga}

Hasil pengujian hipotesis tentang pengaruh corporate social responsibility terhadap agresivitas pajak menunjukkan nilai signifikansi 0,042 lebih kecil dari $\alpha$ $=5 \%$. Hal ini berarti bahwa hipotesis ketiga diterima. Hasil analisis menyatakan bahwa nilai $\mathrm{P}$ value< 0.05 maka variabel $\mathrm{Z}$ (corporate social responsibility) 
Jurnal Akuntansi Manajerial

ISSN (E): 2502-6704

Vol. 6, No. 1 Januari - Juni 2021: 1-17
Dipublikasikan oleh Fakultas Ekonomi dan Bisnis

Universitas 17Agustus 1945 Jakarta

http://journal.uta45jakarta.ac.id/index.php/JAM

terhadap agresivitas pajak berpengaruh. Hasil penelitian ini mendukung penelitian Lanis dan Richardson (2012) dan Huseynov dan Klam (2012), dengan melihat nilai koefisien yang bernilai negatif $(-11,898)$ menunjukan bahwa tingkat pengungkapan CSR yang tinggi dari suatu perusahaan, maka semakin rendah tingkat agresivitas pajak perusahaan tersebut.

\section{Hipotesis Keempat}

Hasil pengujian hipotesis tentang moderasi pengaruh corporate social responsibility atas penerapan PSAK 55 terhadap agresivitas pajak menunjukkan nilai signifikansi 0,749 lebih besar dari $\alpha=5 \%$. Hal ini berarti bahwa hipotesis keempat ditolak. Hasil analisis menyatakan bahwa nilai $\mathrm{P}$ value $>0.05$ maka variabel $\mathrm{Z}$ (corporate social responsibility) tidak berhasil menjadi variabel moderating atas penerapan PSAK 55 terhadap agresivitas. Hasil ini tidak sejalan dengan penelitian yang dilakukan oleh Lee (2015) dan Nurhandono \& Amrie (2017) dan (Hidayat et al., 2016) yang membuktikan bahwa terdapat pengaruh positif signifikan antara perlakuan akuntansi dengan agresivitas pajak, semakin tinggi pengungkapan CSR maka semakin tinggi agresivitas pajak, terutama pada saat perusahaan memanfaatkan instrument keuangan.

\section{Hipotesis Kelima}

Hasil pengujian hipotesis tentang moderasi pengaruh corporate social responsibility atas intensif pajak terhadap agresivitas pajak menunjukkan nilai signifikansi 0,068 lebih besar dari $\alpha=5 \%$. Hal ini berarti bahwa hipotesis kelima ditolak. Hasil analisis menyatakan bahwa nilai $\mathrm{P}$ value $>0.05$ maka variabel $\mathrm{Z}$ (corporate social responsibility) tidak berhasil menjadi variabel moderating atas intensif pajak terhadap agresivitas. Hasil ini tidak sejalan dengan penelitian yang dilakukan oleh (Hidayat et al., 2016) yang semakin tinggi pengungkapan CSR maka semakin rendah agresivitas pajak.

\section{KESIMPULAN}

Berdasarkan hasil analisis, maka ditarik kesimpulan sebagai berikut:

1. Penerapan PSAK 55 (PSAK) tidak berpengaruh terhadap agresivitas pajak, hal ini menunjukan bahwa perubahan regulasi instrument keuangan tidak membawa dampak signifikan pada pelaporan keuangan perusahaan. Metode pengukuran dan pengakuan yang tertuang pada PSAK 55 pada perusahaan property \& real estate yang terdaftar di BEI periode 2015-2019 dinilai sesuai dan tidak mengindikasikan terdapat kesempatan bagi wajib pajak untuk menunda pembayaran, adanya perbedaan tarif antara pajak penghasilan dengan transaksi khusus dan adanya perbedaan perlakuan pajak karena perbedaan karakteristik transaksi yang dapat menimbulkan agresivitas pajak pada perusahaan property \& real estate yang terdaftar di BEI periode 2015-2019.

2. Insentif pajak (TXP) berpengaruh terhadap agresivitas pajak, hal ini menunjukan bahwa pada perusahaan property \& real estate yang terdaftar di BEI periode 2015- 
Jurnal Akuntansi Manajerial

ISSN (E): 2502-6704

Vol. 6, No. 1 Januari - Juni 2021: 1-17
Dipublikasikan oleh Fakultas Ekonomi dan Bisnis

Universitas 17Agustus 1945 Jakarta

http://journal.uta45jakarta.ac.id/index.php/JAM

2019 fasilitas insensif pajak yang diberikan oleh pemerintah berupa penurunan tarif pajak penghasilan dimanfaatkan oleh perusahaan untuk melakukan tax avoidance, hal ini terlihat dari nilai koefisien pada variabel intensif pajak bernilai positif, artinya apabila terjadi peningkatan pada insentif pajak maka agresivitas pajak akan meningkat.

3. Corporate social responsibility (CSR) berpengaruh terhadap agresivitas pajak, hal ini menunjukan bahwa tingkat pengungkapan CSR yang tinggi dari suatu perusahaan, maka semakin rendah tingkat agresivitas pajak perusahaan tersebut.

4. Corporate social responsibility (CSR) tidak berhasil memoderasi penerapan PSAK 55 (PSAK) terhadap agresivitas pajak. Hal tersebut menunjukan bahwa pada saat perusahaan menerapkan instrument keuangan berdasarkan PSAK 55 dalam pengungkapan CSR, perusahaan telah menyadari bahwa CSR merupakan bentuk tanggung jawab perusahaan kepada semua stakeholder dan pajak merupakan salah satu bentuk tanggung jawab sosial perusahaan kepada stakeholder yang diberikan melalui pemerintah.

5. Corporate social responsibility (CSR) tidak berhasil memoderasi insentif pajak terhadap agresivitas pajak, hal tersebut menunjukan bahwa pemberian insentif oleh pemerintah terkait dengan CSR yaitu diperbolehkannya dana CSR sebagai pengurang Penghasilan Kena Pajak (Ph KP) atau tax base yang mengakibatkan Ph KP menjadi lebih kecil bagi organisasi yang melakukan aktivitas CSR, sehingga besaran pajaknya pun akan menjadi lebih kecil dinilai berhasil dalam menghindarkan tindakan agresivitas pajak pada perusahaan property \& real estate yang terdaftar di BEI periode 2015-2019.

\section{SARAN}

Berikut ini merupakan saran untuk berbagai pihak:

1. Bagi perusahaan, penelitian ini diharapkan mampu membantu meningkatkan kinerja keuangan serta tata kelola perusahaan agar lebih baik. Karena dengan adanya peningkatan kinerja keuangan dan tata kelola perusahaan yang lebih baik lagi membuat para investor tertarik untuk berinvestasi pada perusahaan.

2. Bagi investor, dengan adanya laporan tahunan yang tersaji baik dan lengkap pada website perusahaan dapat dijadikan bahan untuk mempertimbangkan investasi yang akan dilakukan pada suatu perusahaan.

3. Bagi penelitian selanjutnya diharapkan untuk:

a. Menambahkan variabel lain yang dapat mempengaruhi agresivitas pajak pada perusahaan atau menambahkan sampel penelitian agar dapat mengetahui pengaruh dari variabel yang telah diuji pada penelitian ini dengan lebih mendalam.

b. Menggunakan indikator atau pengukuran terbaru untuk menguji setiap variabel penelitian.

c. Menambahkan periode penelitian yang lebih panjang agar didapatkan hasil yang lebih akurat. 
Jurnal Akuntansi Manajerial

ISSN (E): 2502-6704

Vol. 6, No. 1 Januari - Juni 2021: 1-17
Dipublikasikan oleh Fakultas Ekonomi dan Bisnis

Universitas 17Agustus 1945 Jakarta http://journal.uta45jakarta.ac.id/index.php/JAM

d. Mempertimbangkan untuk menggunakan objek penelitian seluruh perusahaan yang terdaftar di BEI, sehingga dapat dilihat generalisasi teori secara valid.

\section{DAFTAR PUSTAKA}

Anthony, Robert N., And Vijay Govindarajan. 2012. Management Control Systems : Sistem Pengendalian Manajemen.

Atmajaya, Teguh. 2015. “Analisis Penerapan Sustainability Report Perusahaan Perusahaan Pertambangan Peserta Indonesia Sustainability Reporting Awards ( Isra ) 2013 ( Analysis Of Sustainability Report Implementation On Indonesia Sustainability Reporting Awards ( Isra ) 2013 Min.” Artikel Ilmiah Jember 2013:16.

Detikfinance. 2018. "Berpotensi Lakukan Penghindaran Pajak, 40\% Pengembang Real Estate Perlu Diperiksa." Detikfinance.Com. Retrieved (Https://Finance.Detik.Com/Properti/D-2329288/Berpotensi-Lakukan-

Penghindaran-Pajak-40-Pengembang-Real-Estate-Perlu-Diperiksa-).

Ghozali, Imam. 2016. “Aplikasi Analisis Multivariate Dengan Program Ibm Spss 23.” (Edisi 8). Semarang: Badan Penerbit Universitas Diponegoro.

Abdul, Hasyir Dede, And Ezra Ariwendha. 2017. “Analisis Pengukuran Kinerja Csr Berdasarkan Evaluasi Laporan Berkelanjutan" (Studi Kasus Pada Pt Antam (Persero) Tbk.” Jurnal Akuntansi Dan Keuangan Universitas Padjajaran 17(1):113.

Harini, Gustia, Yesmira Syamra, And Puguh Setiawan. 2020. "Pengaruh Insentif Pajak , Pajak , Dan Cash Flow Terhadap Konservatisme." Jurnal Manajemen Dan Kewirausahaan Vol 11. No(Januari):10-23.

Hidayat, Kholid, Arles P. Ompusunggu, H. Suratno, Magister Akuntansi, Universitas Pancasila, Jl Srengseng Sawah, And Kholid Hidayat. 2016. "Pengaruh Insentif Pajak Terhadap Agresivitas Pajak Dengan Corporate Social Responsibility Sebagai Pemoderasi." Jurnal Ilmiah Akuntansi Fakultas Ekonomi 2(2):39-58.

Lanis, Roman, And Grant Richardson. 2012. "Corporate Social Responsibility And Tax Aggressiveness: An Empirical Analysis." Journal Of Accounting And Public Policy. Doi: 10.1016/J.Jaccpubpol.2011.10.006.

Lee, Yoojin. 2015. "The Impact Of Hedging And Non-Hedging Derivatives On Tax Avoidance." University Of California Phd.

Ningsih, Atika Tri, And Charoline Cheisviyanny. 2019. "Analisis Pengungkapan Corporate Social Responsibility Pt. Bukit Asam, Tbk Berdasarkan Global Reporting Initiatives (Gri) Dan Kaitannya Dengan Proper." Jurnal Eksplorasi 
Jurnal Akuntansi Manajerial

ISSN (E): 2502-6704

Vol. 6, No. 1 Januari - Juni 2021: 1-17
Dipublikasikan oleh Fakultas Ekonomi dan Bisnis

Universitas 17Agustus 1945 Jakarta http://journal.uta45jakarta.ac.id/index.php/JAM

Akuntansi 1(3):846-64.

Nurhandono, Furqon, And Firmansyah Amrie. 2017. "Lindung Nilai, Financial Leverage .." Media Riset Akuntansi, Auditing \& Informasi 17(1):31-52.

Rombe, Astriditta, Hartono Rahardjo, And Susanna Hartanto. 2017. "Penghindaran Pajak Perusahaan ( Studi Empiris Perusahaan Manufaktur Yang Terdaftar." Jurnal Akuntansi Kontemporer 9(2):142-61.

Sekaran, Uma, And Roger Bougie. 2016. "Reserach Methods For Bussiness A SkillBulding Approach.” Printer Trento Srl.

Wikamorys, Dian Anggraini, And Thinni Nurul Rochmach. 2017. "Aplikasi Theory Of Planned Behavior Dalam Membangkitkan Niat Pasien Untuk Melakukan Operasi Katarak." Jurnal Administrasi Kesehatan Indonesia. Doi: 10.20473/Jaki.V5i1.2017.32-40.

Widarjono, Agus. 2013. Ekonometrika : Pengantar Dan Aplikasinya.

Yin, Q. Jennifer, And C. S. Agnes Cheng. 2004. "Earnings Management Of Profit Firms And Loss Firms In Response To Tax Rate Reductions." Review Of Accounting \& Finance. 